\title{
A quantitative comparison of two kits for DNA extraction from canned tuna
}

\author{
Eliska Servusova ${ }^{1,2}$, Vladimir Babak ${ }^{1}$, Zora Piskata ${ }^{1}$, Pavel Krcmar $^{1}$ \\ ${ }^{1}$ Veterinary Research Institute, Brno, Czech Republic \\ ${ }^{2}$ University of Veterinary and Pharmaceutical Sciences Brno, Faculty of Veterinary Hygiene and Ecology, \\ Department of Meat Hygiene and Technology, Brno, Czech Republic
}

Received April 1, 2019

Accepted June 13, 2019

\begin{abstract}
The most common methods that can be used for species identification of tuna include methods based on detection of species-specific DNA via the polymerase chain reaction (PCR) method. The problem with DNA detection in processed products is the possibility of DNA fragmentation during the technological process. The quantity and quality of extracted DNA is a crucial step for species identification based on the DNA analysis. In this study, two DNA extraction methods (DNeasy Blood \& Tissue Kit and DNeasy mericon Food Kit) for tuna DNA isolation were compared. Eight food products of canned tuna (three of them were declared as Thunnus albacares and five products were declared as Katsuwonus pelamis) with a different addition of various ingredients were tested. Furthermore, three different times of proteolysis (30 min, $60 \mathrm{~min}$, overnight) for each sample and each extraction kit were evaluated. The DNA concentration was determined by a Qubit dsDNA HS Assay Kit fluorescence method and quantified using a Qubit fluorometer. The DNA purity was evaluated using the A260/A280 ratio of absorbances measured on a spectrophotometer. The main indicator of DNA quality and quantity was its amplifiability in the subsequent real-time PCR for Thunnus species, Thunnus albacares and Katsuwonus pelamis. Based on the results, both kits can be used for tuna species determination in highly heat-treated products with different composition, nevertheless, the DNeasy mericon Food Kit provided better statistical values in some parameters. The effect of different times of proteolysis was significant in most of the samples with regard to the crossing point values determined by real-time PCR.
\end{abstract}

Canned product, DNA isolation, real-time PCR, Thunnus albacares, Katsuwonus pelamis

Verifying food authenticity is a crucial issue in food safety. The legislation of the Czech Republic is based on the applicable European Union food safety regulations. According to the Council Regulation (EEC) 1536/1992, tuna is divided into genuine tuna and bonito tuna. Consumers need to reliably find accurate labelling of tuna products, in particular an indication of the tuna species name, on the product packaging. Given the increase in demand and consumption of tuna products and the high cost of production, different types of tuna of variable quality can be substituted, which can lead to consumer deception (Espinera et al. 2009). Tuna products are subject to various effects during the manufacturing process (high temperature, pressure, addition of ingredients, etc.) that can greatly affect DNA quality (Cawthorn et al. 2011). In the case of imported tuna, the species verification by morphological features is impossible. Therefore, there is an effort to develop new methods capable of identifying a wide range of fish species in processed products (Lockley and Bardsley 2000). The analytical methods are primarily aimed at detecting protein or DNA molecules that are extracted from fish tissues (Mackie et al. 1999). The primary consideration of any food labelling legislation needs to be to inform and protect consumers. For this reason, verifying declared components in food is essential to protect consumer health (Fajardo et al. 2010; Ali et al. 2012), as well as to ensure a fair trade and compliance with legislation (Ballin et al. 2009; Spink and Moyer 2011; Nakyinsige et al. 2012). DNA can be degraded into smaller fragments during the thermal

Address for correspondence:

Pavel Krcmar.

Department of Food and Feed Safety

Veterinary Research Institute Brno

Hudcova 70, 62100 Brno, Czech Republic

E-mail: krcmarp@post.cz; zorah@email.cz

http://actavet.vfu.cz/ 
process but these are still detectable. Civera (2003) claimed that the canning process degrades DNA to molecules smaller than $123 \mathrm{bp}$ in length. The critical step is to extract high quality DNA in sufficient quantities from heterogeneous food matrices, which can greatly affect DNA quality (Chapela et al. 2007; Besbes et al. 2011), so it is essential to optimize DNA isolation procedures for each type of food product individually. This kind of food (canned tuna) has a really diverse matrix composition, and its constituents can act as PCR inhibitors that can negatively affect the sensitivity of the PCR reaction. This study describes the comparison of two DNA extraction kits (DNeasy Blood \& Tissue Kit and DNeasy mericon Food Kit) and the different proteolysis time on the eight commercial canned tuna products. DNeasy Blood \& Tissue Kit is aimed at the isolation of DNA from tissues (muscles), while DNeasy mericon Food Kit is designed for DNA isolation especially from highly processed food products. Tuna is sold as chilled or frozen muscle (steak) and as canned products. Our aim was to find whether there is a significant difference between these two kits.

\section{Materials and Methods}

Table 1. List of samples.

\begin{tabular}{cll}
\hline Samples & \multicolumn{1}{c}{ Product name } & Declaration \\
\hline 1 & Tuna in brine & T. albacares \\
2 & Tuna steak in sunflower oil & T. albacares \\
3 & Pate tonno e peperoncino & T. albacares \\
4 & Exotic salad with tuna & K. pelamis \\
5 & Tuna with vegetables in dressing sauce & K. pelamis \\
6 & Tuna salad Mexico & K. pelamis \\
7 & Tonno all'olio di oliva & K. pelamis \\
8 & Sweet and sour salad with tuna & K. pelamis \\
\hline
\end{tabular}

\section{Sample preparation}

The study is focused on eight samples of canned tuna purchased on the Czech market. Three were declared as yellowfin tuna (Thunnus albacares) and five samples were declared as skipjack tuna (Katsuwonus pelamis). These eight samples had a different composition with the addition of various ingredients. Each sample was isolated in triplicate for each lysis time. Table 1 shows the list of samples.

DNA isolation

DNA was extracted using two commercially available kits based on the column system (DNeasy Blood \& Tissue Kit (Qiagen, Hilden, Germany), hereinafter B\&T, and DNeasy mericon Food kit (Qiagen, Hilden, Germany), hereinafter Mericon. The B\&T is aimed at the isolation of DNA from tissues (in this case muscle tissue), while the Mericon can be used for the extraction of DNA from highly processed food products including canned products. The extraction procedures were performed according to the protocols supplied by the manufacturers. Sample weight differed: $25 \mathrm{mg}(\mathrm{B} \& \mathrm{~T})$ and $200 \mathrm{mg}$ (Mericon). Proteolysis was carried out for both extraction protocols. The Mericon mixture kit was heated to $60^{\circ} \mathrm{C}$ for 3 different times $(\mathrm{T} 1=30 \mathrm{~min}, \mathrm{~T} 2=2 \mathrm{~h}$ or T3 $=$ overnight $)$ with constant shaking $(1000 \mathrm{rpm})$. The B\&T kit mixture was heated to $56^{\circ} \mathrm{C}$ without shaking for under the same time conditions (T1, T2, T3). Elution solutions of $100 \mu 1$ were used for both kits.

Assessment of DNA quantity

The DNA concentration was determined by the Qubit dsDNA HS Assay Kit (Thermo Fisher Scientific, Waltham, MA, USA) and quantified using a Qubit fluorometer (Thermo Fisher Scientific, Waltham, MA, USA).

Assessment of DNA purity

Samples were measured by a UV spectrophotometer (NanoDrop ${ }^{\mathrm{TM}}$ 1000, Thermo Scientific, Waltham, MA, USA) to gain the A260/A280 ratios. Instrument calibration was performed using the elution buffer. Measurement was done at room temperature following sufficient mixing of all samples.

DNA amplification

For designing primers and probes for real-time PCR amplification of DNA sequence specific for T. albacares, $K$. pelamis and Thunnus sp. the alignment of all sequences of complete mitochondrial DNA of T. albacares and $K$. pelamis with all other mitochondrial DNA sequences of tuna contained in the Gene Bank (https://www. ncbi.nlm.nih.gov/nuccore/) was provided using Blast (https://blast.ncbi.nlm.nih.gov/Blast.cgi). Due to the high homology of the individual gene sequences among tuna species, several regions (T. albacares - NADH dehydrogenase subunit $2 ; \mathrm{K}$. pelamis - cytochrome b; Thunnus sp. - $12 S$ rRNA) were identified, in which specific primers and probes could be designed. The species-specific amplification product of T. albacares was $128 \mathrm{bp}$ (Krcmar et al. Manuscript under preparation) and amplification product of $K$. pelamis was $82 \mathrm{bp}$. 
Further, to control the presence of amplifiable fish DNA (especially tuna) in the sample, primers and probes were designed to determine the portion of the $12 S \mathrm{rRNA}$ mitochondrial gene sequence in the conserved sequence for fish with an amplification product of $80 \mathrm{bp}$.

Sequences of the primers for the species

Thunnus sp.

forward primer 5'-GAGAATGCCCCACAGTTTTC-3'

reverse primer: 5'-AAGCAAGGCGTCATGGG-3'

locked nucleic acid probe: 5'-AGGAGCT-3'

Thunnus albacares

forward primer: 5'-GCAAAAACCCCAGCG-3'

reverse primer: 5'-GGGGCTAGATCTTGCTTTGATAG-3'

probe: 5'-CAGGATTAGTCATTTTGGCATGAAACCTG-3'

Katsuwonus pelamis

forward primer: 5'-TAGACAACGCCACCCTTACC-3'

reverse primer: 5'-CGGTTTCGTGAAGGAATAGG-3'

probe: TCCCCTTCGTCATCGCAGCC-3'

The reaction mixture $(10 \mu \mathrm{l})$ contained $5 \mu \mathrm{l}$ QuantiTect Probe PCR Kit (Qiagen GmbH, Hilden, Germany), $2 \mu \mathrm{l}$ of the DNA sample, $1 \mu \mathrm{l}$ of primer and probe solution $(5 \mu \mathrm{M}$ of each primer and $1 \mu \mathrm{M})$ probes $)$, and $2 \mu 1 \mathrm{H}_{2} \mathrm{O}$. Amplification was performed with the LightCycler 1.5 instrument (Roche Diagnostics International Ltd., Rotkreuz, Switzerland) with the following programme: Initial denaturation $\left(50{ }^{\circ} \mathrm{C}\right.$ for 2 min and $95{ }^{\circ} \mathrm{C}$ for $15 \mathrm{~min}$ ), amplification ( 40 cycles of $95^{\circ} \mathrm{C}$ for $15 \mathrm{~s}$, and $60^{\circ} \mathrm{C}$ for $60 \mathrm{~s}$ - fluorescence is scanned in this step).

Statistical analysis

Based on these tests (Brown-Forsythe test, ANOVA method, Tukey with HSD post hoc test, Wilcoxon matchedpairs signed rank test, and Chi-squared test), data analysis was performed using Statistica 13.2 statistical software (StatSoft Inc., Tulsa, OK, USA) and GraphPad Prism 5.04 (GraphPad Software Inc., San Diego, CA) for this study. $P$ values less than 0.05 were considered significant.

\section{Results}

The aim of this work was to quantitatively compare two kits for DNA isolation from heattreated tuna samples. Main attention was paid to the results of real-time PCR determination of DNA of Thunnus sp., T. albacares and $K$. pelamis isolated via both kits and using three proteolysis times. The results will be divided into subchapters and analyzed subsequently. The main focus was aimed at the results of real-time PCR analysis expressed by the crossing point (Cp) which is the point at which the fluorescence of the sample rises above the background fluorescence. The lower the Cp, the more DNA the sample contains.

\section{Crossing point for the Thunnus species}

The Cp values for the Thunnus sp. were analysed for each sample by two-way ANOVA in a factorial design (including interaction), with the factors kit (B\&T, Mericon) and time (three levels: $\mathrm{T} 1=30 \mathrm{~min}, \mathrm{~T} 2=2 \mathrm{~h}, \mathrm{~T} 3=$ overnight). Compliance with the assumptions of the ANOVA method was verified using externally studentized residuals (standard normal distribution) and Brown-Forsythe test (homogeneity of variances). The results are shown in Table 2.

It is evident from Table 2 that the kit was a significant factor $(P<0.05$ at least $)$ in seven samples. Four samples showed significant changes during time, which showed up at T3 compared to the initial time T1 $(P<0.05$ at least). The contrast (mean difference between the two kits) is indicated in the samples with a significant difference between the kits. Table 2 shows that the $\mathrm{Cp}$ values are significantly higher (worse) in the case of the B\&T kit in five cases. In the last column, $\mathrm{R}^{2}$ is the value that allows us to assess how well the ANOVA model has captured empirical data (e.g., 0.7752 for sample 1 can be interpreted as explaining nearly $78 \%$ of the data variability, a very good result). For sample $4, \mathrm{R}^{2}$ is only 0.52. The cause is $\mathrm{Cp} 25.87$ (B\&T, T1), which is too low in the context of other values 
Table 2. Crossing point (Cp) values for the Thunnus species.

\begin{tabular}{|c|c|c|c|c|c|}
\hline Sample & & cance of $\mathrm{f}$ & & Contrast & $\mathrm{R}^{2}$ \\
\hline & Kit & Time & Kit*Time & B\&T - Mericon & \\
\hline 1 & $P<0.01$ & ns & $\mathrm{ns}$ & 0.9900 & 0.7752 \\
\hline 2 & $P<0.01$ & $P<0.01$ & ns & 1.9422 & 0.9882 \\
\hline 3 & $P<0.01$ & ns & ns & 3.6344 & 0.9793 \\
\hline 4 & ns & $P<0.05$ & ns & & 0.5201 \\
\hline 5 & $P<0.01$ & $P<0.01$ & ns & 1.5178 & 0.8582 \\
\hline 6 & $P<0.01$ & ns & ns & 3.7572 & 0.9580 \\
\hline 7 & $P<0.01$ & ns & ns & 2.0589 & 0.8576 \\
\hline 8 & $P<0.01$ & $P<0.05$ & ns & -1.2611 & 0.8349 \\
\hline
\end{tabular}

ns - not significant; $\mathrm{R}^{2}$ - determination coefficient

Contrast (mean difference between the two kits) is indicated in samples with a significant difference between the kits.

(ext. studentized residual is 3.40 for this measured value). In this case, the sample could be erroneously measured.

Figure 1 (Plate IV) shows the values for each sample based on Table 2.

Table 3. The comparison of time (T1, T2, T3) between the two kits (significant $P<0.01$ - samples 2, 5; Thunnus sp.).

\begin{tabular}{lccc}
\hline Time & T1 & T2 & T3 \\
\hline T1 & & ns & $P<0.01$ \\
T2 & ns & & ns \\
T3 & $P<0.01$ & ns & \\
\hline T1 = 30 min; T2 $=2$ h; T3 = overnight; & ns - not significant
\end{tabular}

Table 4. The comparison of time (T1, T2, T3) between the two kits (significant $P<0.05$ - samples 4, 8; Thunnus sp.).

\begin{tabular}{lccc}
\hline Time & T1 & T2 & T3 \\
\hline T1 & & $P<0.05$ & $P<0.05$ \\
T2 & ns & & ns \\
T3 & $P<0.05$ & $P<0.05$ & \\
\hline
\end{tabular}

$\mathrm{T} 1=30 \mathrm{~min} ; \mathrm{T} 2=2 \mathrm{~h} ; \mathrm{T} 3=$ overnight; $\mathrm{ns}-$ not significant
It can be observed in sample 2 that both lines are almost parallel, reflecting the fact that the interaction of both factors is not significant. On the other hand, the distance of both lines is large (contrast is 1.9422), which is reflected in the significance of the kit factor (therefore, the $\mathrm{Cp}$ values for both kits are significantly different). In addition, both lines have a relatively clear downward trend over time, which is reflected in the significance of time. This factor has three levels, so it is worth asking among which levels of this factor there are significant differences, which we test using Tukey's HSD post hoc test. Up to T3, a significant decrease in the Cp versus time T1 (both kits) occurred (Table 3).

In sample 2, differences between kits were significant (both lines are far apart). Changes over time, considering the variability indicated, are too small to be significant, which is consistent with the "ns" value in the time column of sample 3.

Sample 4 shows that the line, corresponding to the Mericon kit, is above the B\&T kit line, but the indicated variability (vertical bars) is relatively high, so the significant difference between the kits was not demonstrated. However, the trend of time changes (a decrease) is evident and similar for both kits. Therefore, time came out as a significant factor (changes in time for both kits are significant) where the significance is the same as in Table 3.

Sample 5 shows that $\mathrm{Cp}$ values were significantly affected by both the kit factor and the time factor. Up to T3, a significant decrease can be seen in the Cp versus time T1 for both kits (Table 3). Sample 6 shows the changes over time were not significant, with a significant difference between the kit values.

Changes over time in sample 7 were not significant; there was a significant difference 
Table 5. Crossing point (Cp) for Thunnus albacares/Katsuwonus pelamis.

\begin{tabular}{|c|c|c|c|c|c|}
\hline \multicolumn{2}{|c|}{ Sample } & \multicolumn{2}{|c|}{ Significance of factors } & \multirow{2}{*}{$\frac{\text { Contrast }}{\text { B\&T - Mericon }}$} & \multirow[t]{2}{*}{$\mathrm{R}^{2}$} \\
\hline & Kit & Time & Kit*Time & & \\
\hline 1 & $P<0.01$ & $P<0.01$ & $P<0.01$ & & 0.8637 \\
\hline 2 & $P<0.01$ & $P<0.05$ & ns & 2.1422 & 0.9681 \\
\hline 3 & $P<0.01$ & ns & $\mathrm{ns}$ & 4.0322 & 0.9888 \\
\hline 4 & $P<0.01$ & $P<0.05$ & $\mathrm{~ns}$ & 1.1067 & 0.8487 \\
\hline 5 & $P<0.01$ & $P<0.01$ & ns & 3.1144 & 0.9618 \\
\hline 6 & $P<0.01$ & $P<0.05$ & $\mathrm{~ns}$ & 4.2967 & 0.9825 \\
\hline 7 & $P<0.01$ & ns & ns & 3.2833 & 0.9310 \\
\hline 8 & $P<0.01$ & $P<0.01$ & ns & 0.8367 & 0.7540 \\
\hline
\end{tabular}

$\mathrm{ns}$ - not significant; $\mathrm{R}^{2}$ - determination coefficient

Contrast (mean difference between the two kits) is indicated in samples with a significant difference between the kits.

between kit values. The $\mathrm{Cp}$ values of sample 8 were significantly affected by the kit and changed significantly over time. At times T2 and T3, there was a significant decrease in Cp.

Crossing point for Thunnus albarares/Katsuwonus pelamis

The Cp values were analysed according to the same procedure as for the Thunnus sp. The following Table 5 shows the results of how factors in individual samples affected the Cp values.

The table shows that the kit was a significant factor $(P<0.01)$ in all 8 samples, time in 6 samples and a significant interaction of both factors in sample 1. The contrast (mean difference between the two kits) is shown for those samples where a significant difference between the kits (for sample 1, it does not make sense because of a significant interaction). It is shown in the table that the $\mathrm{Cp}$ values are in all cases significantly higher (worse) for the B\&T kit. From the high $\mathrm{R}^{2}$ values, it is evident that the ANOVA model well captured the empirical data.

Figure 2 (Plate V) again describes individual samples for interaction of the $\mathrm{Cp}$ and exposure time.

All eight samples showed a significant difference between the kits $(P<0.01$; ANOVA and Tukey's HSD post hoc test; see Table 5, column kit and Fig. 2, samples 1-8), with the Mericon kit always being better (lower mean $\mathrm{Cp}$ ). The mean $\mathrm{Cp}$ difference of both kits ranged from 0.84 (sample 8) to 4.30 (sample 6); see Table 5, column contrast.

All samples except samples 3 and 7 showed significant changes in the Cp values over time, with the dominant trend being a decrease in mean $\mathrm{Cp}$ values at overnight time vs. $30 \mathrm{~min}$ and $120 \mathrm{~min}(P<0.05$ at least; ANOVA and Tukey's HSD post hoc test; see Table 5, time and Fig. 2). For sample 1, the interaction of both factors, and different behaviour of both kits over time ( $P<0.01$; ANOVA and Tukey's HSD post hoc test; see Table 5, time and Fig. 2) was demonstrated: the Cp detected by the Mericon kit dropped over time, but remained constant when detected by the B\&T kit.

DNA concentration (ng DNA/mg tissue)

From the values of measured DNA concentration of individual samples, we performed basic statistical analysis providing further information for evaluation (Table 6).

It is evident from Table 6 that the values of ng DNA / $\mathrm{mg}$ of tissue in the B\&T kit were significantly higher than in the Mericon kit. This was confirmed by the Wilcoxon matchedpairs signed rank test $(P<0.01)$.

Furthermore, the correlation between DNA concentration and $\mathrm{Cp}$ values for both kits was evaluated. The results are found in Table 7 showing the values of the Spearman correlation coefficients. 
Table 6. Descriptive statistics for ng DNA/mg tissue.

\begin{tabular}{lrr}
\hline Descriptive statistics & Mericon & \multicolumn{1}{c}{ B\&T } \\
\hline Number of values & 72 & 72 \\
Minimum & 0.1230 & 0.3980 \\
25\% Percentile & 0.2318 & 0.7745 \\
Median & 0.2890 & 1.0925 \\
$75 \%$ Percentile & 0.3413 & 3.7398 \\
Maximum & 0.6160 & 16.8000 \\
Mean & 0.3027 & 2.8043 \\
Std. deviation & 0.1151 & 3.2875 \\
Std. error & 0.0136 & 0.3874 \\
Lower 95\% CI of mean & 0.2757 & 2.0318 \\
Upper 95\% CI of mean & 0.3298 & 3.5769 \\
\hline
\end{tabular}

Number of values (8 samples; every sample was lysed with times T1, T2, T3; every sample was measured with three targeted genes, for Thunnus sp., Thunnus albacares and Katsuwonus pelamis).

Std. deviation; standard deviation is a statistic that measures the dispersion of a dataset relative to its mean and is calculated as the square root of the variance.

Std. error; standard error of a statistic (usually an estimate of a parameter) is the standard deviation of its sampling distribution or an estimate of that standard deviation.

A $95 \%$ confidence level means that $95 \%$ of the sample data lie within the confidence interval (CI).

Table 7. Correlation between DNA concentration and crossing point (Cp) values for both kits.

\begin{tabular}{llc}
\hline Correlation & Mericon & B\&T \\
\hline Cp Thunnus sp. vs. ng DNA/mg tissue & $-0.2382^{*}$ & 0.1721 \\
Cp T. alba/pel vs. ng DNA/mg tissue & -0.0975 & $-0.3916^{*}$ \\
\hline
\end{tabular}

* Significant values $(P<0.05$ at the least $)$

Table 8. Absorbance values for the Mericon kit.

\begin{tabular}{lccccccccc}
\hline Category & Sample 1 & Sample 2 & Sample 3 & Sample 4 & Sample 5 & Sample 6 Sample 7 & Sample 8 & Total \\
\hline$<1.7$ & 0 & 2 & 5 & 2 & 0 & 4 & 4 & 1 & 18 \\
$1.7-2.0$ & 7 & 5 & 4 & 7 & 9 & 4 & 5 & 6 & 47 \\
$>2.0$ & 2 & 1 & 0 & 0 & 0 & 1 & 0 & 2 & 6 \\
\hline$<1.7$ & 0.00 & 25.00 & 55.56 & 22.22 & 0.00 & 44.44 & 44.44 & 11.11 & $25.35[\%]$ \\
$1.7-2.0$ & 77.78 & 62.50 & 44.44 & 77.78 & 100.00 & 44.44 & 55.56 & 66.67 & $66.20[\%]$ \\
$>2.0$ & 22.22 & 12.50 & 0.00 & 0.00 & 0.00 & 11.11 & 0.00 & 22.22 & $8.45[\%]$ \\
\hline
\end{tabular}

Table 9. Absorbance values for the B\&T kit.

\begin{tabular}{lccccccccc}
\hline Category & Sample 1 & Sample 2 & Sample 3 & Sample 4 & Sample 5 & Sample 6 Sample 7 & Sample 8 & Total \\
\hline$<1.7$ & 0 & 6 & 0 & 0 & 0 & 0 & 3 & 0 & 9 \\
$1.7-2.0$ & 6 & 2 & 9 & 5 & 9 & 6 & 5 & 9 & 51 \\
$>2.0$ & 3 & 1 & 0 & 4 & 0 & 3 & 1 & 0 & 12 \\
\hline$<1.7$ & 0.00 & 66.67 & 0.00 & 0.00 & 0.00 & 0.00 & 33.33 & 0.00 & $12.68[\%]$ \\
$1.7-2.0$ & 66.67 & 22.22 & 100.00 & 55.56 & 100.00 & 66.67 & 55.56 & 100.00 & $70.42[\%]$ \\
$>2.0$ & 33.33 & 11.11 & 0.00 & 44.44 & 0.00 & 33.33 & 11.11 & 0.00 & $16.90[\%]$ \\
\hline
\end{tabular}

The strength of correlation can be marked as "weak" for both significant results. Obviously, the results cannot be overestimated, but they suggest that the kits behave a little differently. While in the Mericon, it is possible to speak about a proven trend of decreasing ng DNA/mg tissue values with the increasing $\mathrm{Cp}$ in the Thunnus sp., in the B\&T kit, ng DNA/mg tissue values were decreasing with the increasing $\mathrm{Cp}$ values in T. albacares/K. pelamis.

Absorbance values A260/A280

The purities were estimated by calculating the A260/A280 ratios. Samples calculated to have A260/A280 ratios of 1.7-2.0 were assumed to be pure, free from protein and other contaminants. Values of A260/A280 are thus divided into three categories: $<1.7 ; 1.7$ to 2.0 (optimal), and $>2.0$. We then counted for each sample and both kits how many A260/A280 values belong to each of the categories listed in Tables 8 and 9 for the Mericon and B\&T. In sample 2, eight measurements instead of the typical nine in other samples were done because 
this one sample form the triplicatewas probably contaminated during themanipulationand the A260/A280 ratio reached 3.13. Therefore, this measurement was not calculated.

Both kits have a comparable proportion of optimum results, the B\&T kit has a lower suboptimal result, but a higher proportion of results $>2.0$, so it has not been shown that kits differ significantly in the A260/A280 distribution ( $P>0.05$, Chi-squared test).

\section{Discussion}

The correct choice of the DNA extraction and DNA quantification method is a very important step in the analytical procedure to ensure optimal results (Barbaro et al. 2004). The DNA extraction methods have an impact on the quantity and quality of the extracted DNA and, therefore, on the efficiency of the DNA amplification (Di Bernardo et al. 2007). Canned products are subjected to physico-chemical treatments (high temperature, preservation process, the time of application, $\mathrm{pH}$ ), but also the addition of some ingredients into these products may play a significant role in DNA extraction from the products (Camma et al. 2012; Piskata et al. 2019). These conditions are probably the result of fragmentation, which is the breakdown into smaller segments of DNA molecules. To choose an optimal extraction procedure, several factors have to be taken into account. DNA should contain as little protein, RNA, organic compounds or any other PCR inhibitors as possible. DNA concentrations were determined fluorometrically by measuring DNA and the quality of extracted DNA was evaluated using the ratio A260/A280 (Chapela et al. 2007). The DNA was considered to be satisfactorily pure when the ratios of the A260 to A280 were within the range of 1.7-2.0. DNA contamination with proteins usually reduces the A260 to A280 ratio to values lower than 1.7 (Cawthorn et al. 2011; Piskata et al. 2017). DNA is very sensitive to acid and alkaline agents, because of the mechanism of hydrolytic degradation of DNA (Peano et al. 2004; Chapela et al. 2007), and low pH media have been described as favouring a higher DNA degradation (Bauer et al. 2003; Chapela et al. 2007). Our DNA purity values were optimal for both kits and in the majority of cases were in the correct range.

The quantity of targeted DNA was measured via real-time PCR method using primers amplifying fragments of mitochondrial DNA. The $\mathrm{Cp}$ value for Thunnus sp. for the kit was significant in 7 samples out of $8(P<0.05$ at least $)$, in the $T$. albacares/K. pelamis $\mathrm{Cp}$, a significant factor $(P<0.01)$ was seen in all 8 samples. The $\mathrm{Cp}$ for the time factor was significant in 4 samples in Thunnus sp., and in 6 samples in the $T$. albacares/K. pelamis Cp. Significance was assessed for samples 2, 4, 5 and 8. Comparison of the three periods of application $(\mathrm{T} 1=30 \mathrm{~min}, \mathrm{~T} 2=2 \mathrm{~h}$, and $\mathrm{T} 3=$ overnight $)$ to the kit was not significant for any of the 8 samples for Thunnus sp. For the $T$. albacares/K. pelamis $\mathrm{Cp}$ came interaction of both factors for sample $1(P<0.01)$. An important indicator of the model's suitability is the coefficient of determination $\mathrm{R}^{2}$, which is sometimes interpreted as a match model with data. The high $\mathrm{R}^{2}$ values of all samples for both Thunnus $\mathrm{sp}$. and T. albacares and $K$. pelamis suggest how the ANOVA model has well captured empirical data. The lowest value $(52 \%)$ for sample 4 was due to the $\mathrm{Cp}$ (25.87; B\&T, T1). Otherwise, the values were higher than $75 \%$.

By determining the DNA concentration (ng DNA/mg tissue) using the Qubit dsDNA HS Assay Kit, we were able to determine the difference in behaviour of both kits. Significantly higher concentrations of DNA were generally detected with the B\&T kit than with the Mericon kit. However, the concentration in this case did not play such an important role, just the correlation between the targeted DNA concentration and the $\mathrm{Cp}$ values as shown above. Except for one sample, the Mericon kit showed lower $\mathrm{Cp}$ values despite lower DNA concentration measured via the Qubit. The correlation suggests different behaviour of the kits. To our best knowledge, no reports have been published regarding the correlation between total DNA concentration in the sample and the amount of real-time PCR product for the determination of the $\mathrm{Cp}$ values. 
For determination of the Thunnus sp. according to the $\mathrm{Cp}$ values determined by realtime PCR, both kits yielded comparable results in two samples, while the Mericon kit demonstrated lower $\mathrm{Cp}$ (it means higher concentration of target amplificable DNA) in five samples, and in one sample lower $\mathrm{Cp}$ values were achieved using B\&T kit. In all three T. albacares samples lower $\mathrm{Cp}$ values were reached using the Mericon kit; equally, in all five $K$. pelamis samples lower Cp values were reached by the Mericon kit. No correlation was found between the DNA concentration measured using the Qubit fluorometer and $\mathrm{Cp}$ values determined by real-time PCR. Similarly, no correlation was found between the A260/A280 ratio and the Cp values determined by real-time PCR. The effect of different times of proteolysis was significant in most of the samples with regard to the $\mathrm{Cp}$ values determined by real-time PCR. Our results show that for the isolation of DNA from canned tuna both commercially available kits can be used. Nevertheless, the DNeasy mericon Food Kit provided better statistical values in some parameters.

\section{Acknowledgements}

This work was supported by the Ministry of Agriculture (grants QJ1530272 and RO0518) and IGA VFU 214/2017/FVHE.

\section{References}

Ali ME, Hashim U, Mustafa S, Che Man YB, Dhahiths KM 2012: Analysis of pork adulteration in commercial meatballs targeting porcine-specific mitochondrial cytochrome $\mathrm{b}$ gene by TaqMan probe real-time polymerase chain reaction. Meat Sci 91: 454-459

Ballin NZ, Vogensen FK, Karlsson AH 2009: Species determination - can we detect and quantify meat adulteration? Meat Sci 83: 165-174

Bauer T, Weller P, Hammes WP, Hertel C 2003: The effect of processing parameters on DNA degradation in food. European Food Res Technol 217: 338-343

Barbaro A, Staiti N, Cormaci P, Saravo L 2004: DNA profiling by different extraction methods. Int Cong Series 1261: $562-564$

Besbes N, Fattouch, S, Sadok S 2011: Comparison of methods in the recovery and amplificability of DNA from fresh and processed sardine and anchovy muscle tissue. Food Chem 129: 665-671

Camma C, Di Domenico M, Monaco F 2012: Development and validation of fast real-time PCR assays for species identification in raw and cooked meat mixtures. Food Control 23: 400-404

Cawthorn D, Steinman HA, Witthuhn RC 2011: Comparative study of different methods for the extraction of DNA from fish species commercially available in South Africa. Food Control 22: 231-244

Chapela MJ, Sotelo CG, Pérez-Martin RI, Pardo MA, Pérez-Villareal B, Gilardi P, Riese J 2007: Comparison of DNA extraction methods from muscle of canned tuna for species identification. Food Control 18: 1211-1215

Civera T 2003: Species identification and safety of fish products. Vet Res Commun 27: 481-489

Council Regulation (EC) No 1536/92 of the European Parliament and of the Council of 9 June 1992 laying down common marketing standards for preserved tuna and bonito. Official Journal L163, 17.6.1992, pp. 1-4

Di Bernardo G, Del Gaudio S, Galderisi U, Casino A, Cipollaro M 2007: Comparative evaluation of different DNA extraction procedures from food samples. Biotechnol Progr 23: 297-301

Espineira M, Gonzalez-Lavín N, Vieites JM, Santaclara FJ 2009: Development of a method for the identification of scombroid and common substitute species in seafood products by FINS. Food Chem 117: 698-704

Fajardo V, Gonzáles I, Rojas M, García T, Martín R 2010: A review of current PCR-basedmethodologies for the authentication of meats from game animal species. Trends Food Sci Tech 21: 408-421

Lockey AK, Bardsley RG 2000: DNA-based methods for food authentication. Trends Food Sci Tech 11: 67-77

Mackie IM, Pryde SE, Gonzales-Scotelo C, Medina I, Peréz-Martín R, Quinteiro J, Rey-Man-Dez M, Rehbein NH 1999: Challenges in the identification of species of canned fish. Trends Food SciTech 10: 9-14

Nakiysinge K, Che Man YB, Sazili AQ 2012: Halal authenticity issues in meat and meat products. Meat Sci 91: 207-214

Peano C, Samson MC, Palmieri L, Gulli M, Marmiroli N 2004: Qualitative and quantitative evaluation of genomic DNA extracted from GMO and Non-GMO Foodstuffs with four different extraction methods. J Agric Food Chem 52: 6962-6868

Piskata Z, Servusova E, Babak V, Nesvadbova M, Borilova G 2019: The quality of DNA isolated from processed food and feed via different extraction procedures. Molecules 24: 1-10

Piskata Z, Pospisilova E, Borilova G 2017: Comparative study of DNA extraction methods from fresh and processed yellowfin tuna muscle tissue. Int J Food Prop 20: 430-443

Spink J, Moyer DC 2011: Defining the public health threat of food fraud. J Food Sci 76: 157-163 
Plate IV

Servusová E. et al.: A quantitative comparison... pp. 315-322
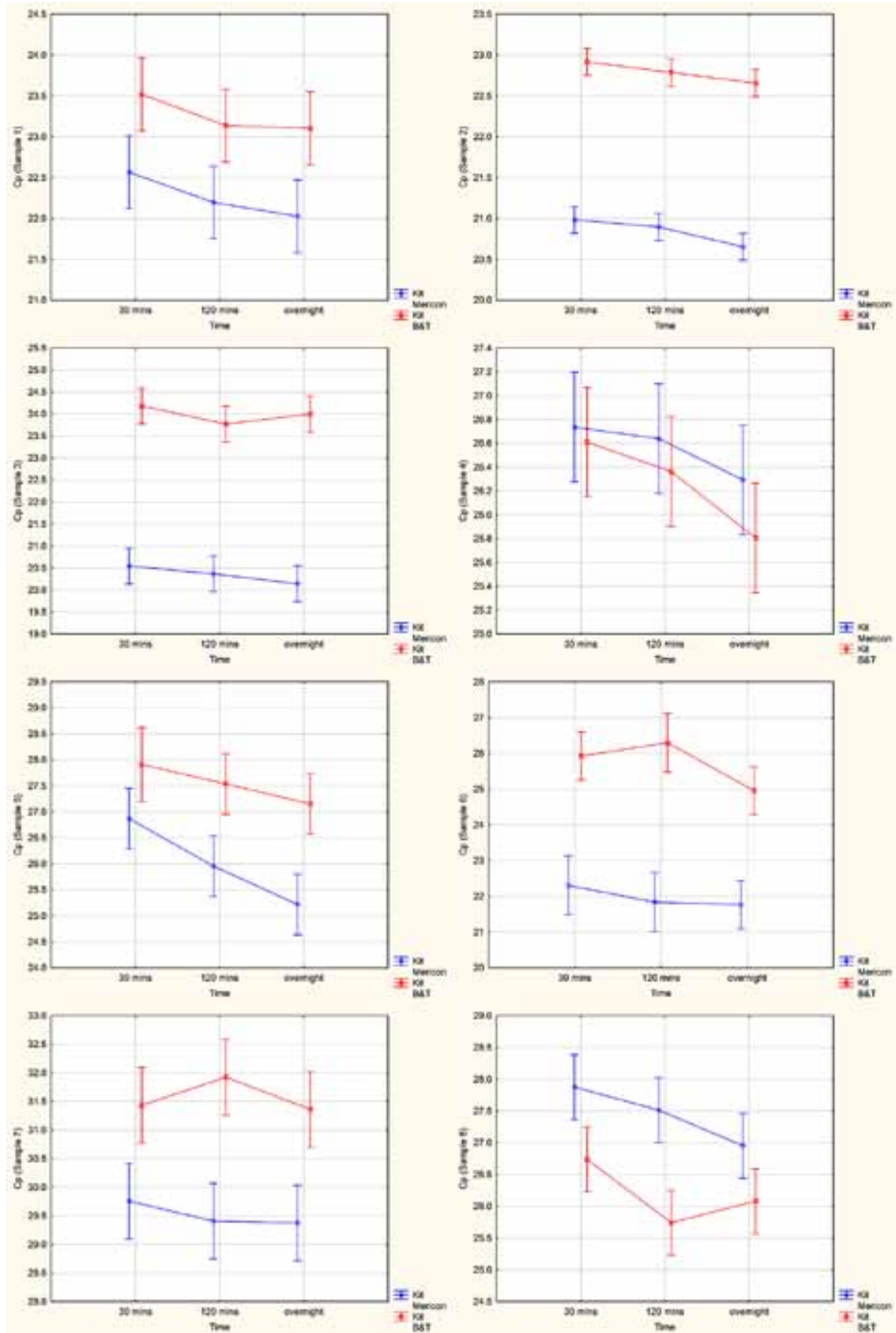

Fig. 1. Crossing point $(\mathrm{Cp})$ values vs. proteolysis time for samples 1-8 using kits B\&T and Mericon; Thunnus sp. 
Plate V
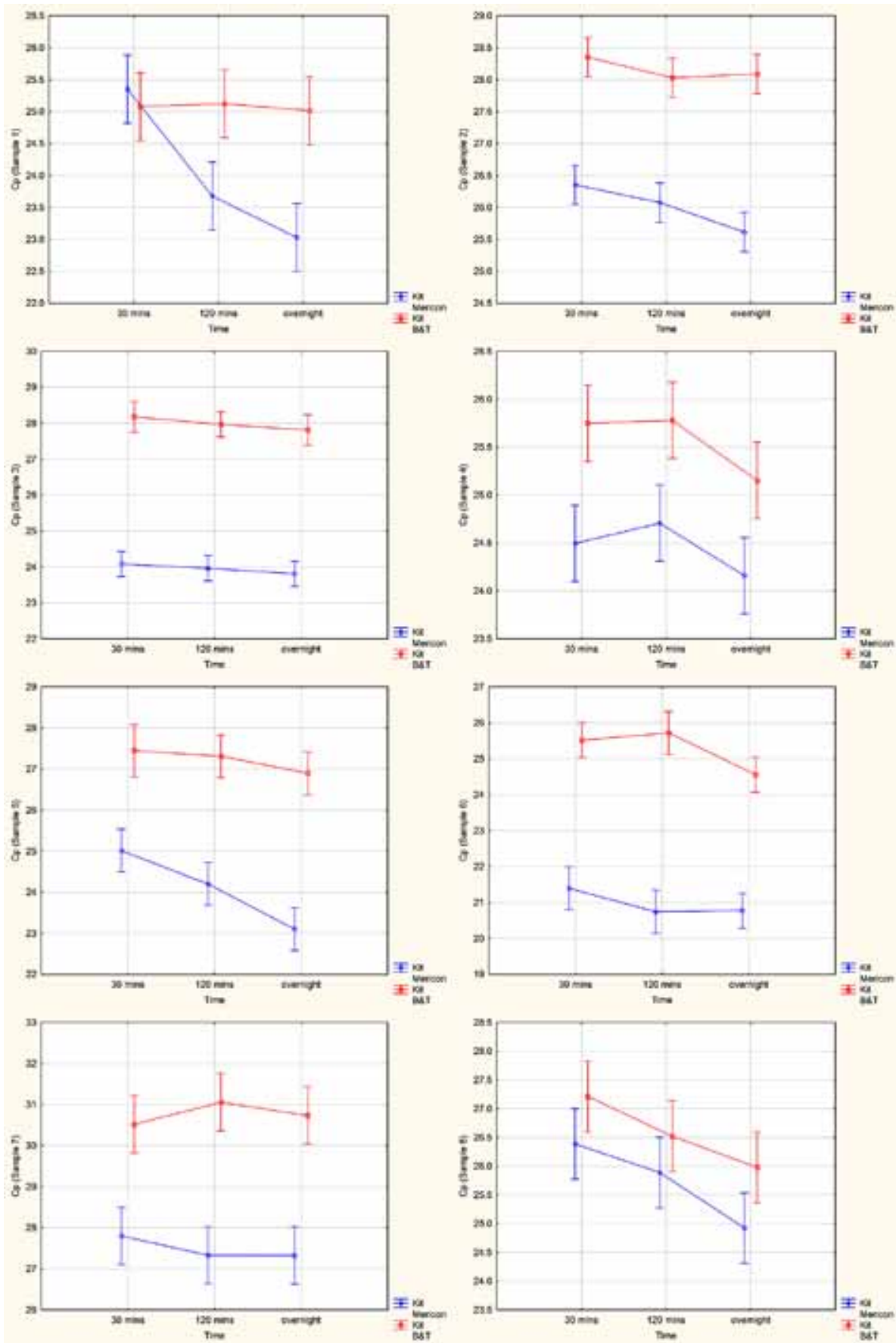

Fig. 2. Crossing point $(\mathrm{Cp})$ values vs. proteolysis time for samples $1-8$ using kits B\&T and mericon; $T$. albacares $/ K$. pelamis. 